\title{
Nanogravimetric and Optical Characterizations of Thrombin Interaction with a Self-Assembled Thiolated Aptamer
}

\author{
Jane Politi, ${ }^{1,2}$ Ilaria Rea, ${ }^{1}$ Fabrizia Nici, ${ }^{3}$ Principia Dardano, ${ }^{1}$ Monica Terracciano, ${ }^{1,3}$ \\ Giorgia Oliviero, ${ }^{3}$ Nicola Borbone, ${ }^{3}$ Gennaro Piccialli, ${ }^{3}$ and Luca De Stefano ${ }^{1}$ \\ ${ }^{1}$ Institute for Microelectronics and Microsystems, National Research Council, Unit of Naples, Via P. Castellino 111, 80131 Naples, Italy \\ ${ }^{2}$ Department of Chemistry, University of Naples "Federico II", Via Cynthia, 80126 Naples, Italy \\ ${ }^{3}$ Department of Pharmacy, University of Naples Federico II, 80138 Naples, Italy \\ Correspondence should be addressed to Luca De Stefano; luca.destefano@na.imm.cnr.it
}

Received 12 February 2016; Accepted 3 April 2016

Academic Editor: Maria Luz Rodríguez-Méndez

Copyright (C) 2016 Jane Politi et al. This is an open access article distributed under the Creative Commons Attribution License, which permits unrestricted use, distribution, and reproduction in any medium, provided the original work is properly cited.

\begin{abstract}
Efficient biorecognition of thrombin (TB), a serine protease with crucial role in physiological and pathological blood coagulation, is a hot topic in medical diagnostics. In this work, we investigate the ability of synthetic thrombin aptamer (TBA), immobilized on a gold substrate, to bind thrombin by two different label-free techniques: the quartz crystal microbalance (QCM) and the spectroscopic ellipsometry (SE). By QCM characterization in the range from 20 to $110 \mathrm{nM}$, we demonstrate high specificity of TBA-TB interaction and determine affinity constant $\left(K_{d}\right)$ of $17.7 \pm 0.3 \mathrm{nM}$, system sensitivity of $0.42 \pm 0.03 \mathrm{~Hz} \mathrm{nM}^{-1}$, and limit of detection (LOD) of $240 \pm 20 \mathrm{pM}$. The interaction between TBA and TB is also investigated by SE, an all-optical method, by quantifying the thickness increase of the TBA film assembled on gold substrate. AFM characterization of TBA and TB molecules deposited on flat silicon surface is also supplied.
\end{abstract}

\section{Introduction}

Thrombin (TB) is a strong vasoconstrictor involved as main agent in vasospasm [1]. Beyond its key role in the dynamic process of thrombus formation, TB has a pronounced proinflammatory character, which may influence the development and progression of atherosclerosis [2]. Concentration levels of TB in human blood around $5 \div 10 \mathrm{nM}$ have been correlated to growth process of tumor cells [3]. It is well known that TB molecules expose two electropositive exosites that specifically interact with substrates: fibrinogen recognition exosite, at the base of the active-site cleft, and heparin recognition exosite $[4,5]$; both substrates, fibrinogen and heparin, are molecules of crucial importance in coagulation/anticoagulation mechanisms [6]. Therefore, the specific recognition and quantitative detection of TB blood concentration in the $\mathrm{nM}$ range play a crucial role in fundamental research as well as to clinical practice [7].

These are the reasons justifying the design and realization of a real-time, highly specific biosensor for thrombin detection in early diagnosis of cardiovascular diseases. The demand of biomolecular probes, alternative to peptides and antibodies in biochemical sensing applications, is nowadays growing in order to avoid time-consuming steps required by labeling and offline analysis.

Aptamers are oligonucleotides sequences of DNA or RNA of variable length, generally between 15 and 80 bases that bind a specific target molecule, selected in vitro by systematic evolution of ligands (SELEX) [8]. The SELEX process, a multisteps procedure, selects the oligonucleotide sequences, which will form the aptamer, on the basis of their specific binding affinity to a target analyte, chosen from a library of sequences. By this kind of approach, a large number of aptamers have been discovered for diagnostics, therapeutics, and other biotechnical applications [9]. Aptamers are known for their specificity: on the basis of slight differences, such as the presence or the absence of hydroxyl or methyl groups in chemical structure [10-13], they are able to discriminate between D-enantiomer and L-enantiomer of the target molecules [14]. The central feature of aptamers 
is the high affinity to targets, which was found comparable to corresponding monoclonal antibodies and characterized by affinity constant values in the picomolar range [10]. Aptamers affinity and specificity properties highlight their huge potential in diagnostic, therapeutic, and (bio)analytical applications [15-17]. The thrombin binding aptamer (TBA) is a classic example of a nucleic acid with potential therapeutic and/or diagnostic ability. TBA adopts a monomolecular chair-like G-quadruplex structure consisting of two G-tetrads connected by two laterals TT and central TGT loops [18]. In presence of thrombin, TBA folds into a specific threedimensional structure that ensures high thrombin binding affinity, depending on ionic strength, $\mathrm{pH}$, and coadsorbent molecules [19-21].

In this work, we studied the interaction between TBA, once immobilized on a gold substrate, and TB by two different label-free methods: quartz crystal microbalance (QCM) and spectroscopic ellipsometry (SE). Quartz crystal microbalance (QCM) based biosensors have received an increasing interest in recent years due to their high sensibility and the ability to perform a real-time monitoring [22-24]. Nanogravimetry exploits the piezoelectric quartz resonator $(\mathrm{QR})$ properties as transducer in quantifying the resonance frequency shift $\Delta f$ when a mass $m$ is adsorbed to/desorbed from its surface [25]. The results of gravimetric analysis were completed by spectroscopic ellipsometry, a powerful optical technique to investigate optical properties (complex refractive index) and thickness of thin films. Both analytical techniques demonstrated the ability of TBA to selectively bind TB, even if it is covalently bound on a modified gold surface.

\section{Experimental Section}

2.1. Aptamer Synthesis and Purification. The thiolated-thrombin binding aptamer (TBA-SH) (4726 Da) was synthesized by Expedite 8909 DNA synthesizer (Applied Biosystems, USA) using standard solid phase $\beta$-cyanoethylphosphoramidite chemistry on a Controlled Pore Glass (CPG) resin, as previously reported [26]. Last coupling step was performed with a proper thiol-modified phosphoramidite (dithiothreitol group, DTT). All the reagents and the CPG support were purchased from Glen Research. The oligomers were detached from the resin and deprotected by treatment with aqueous ammonia at $55^{\circ} \mathrm{C}$, overnight. The combined filtrates and washing were purified through reverse phase HPLC (Purospher STAR, $5 \mu \mathrm{m}, 250 \times 10 \mathrm{~mm}$, Merck), to allow the identification of our product as the most retained peak, by virtue of the presence of the trityl group protecting the thiol function. We used a linear gradient from $0 \%$ to $100 \% \mathrm{~B}$ for $30^{\prime}$ and flow rate $1.2 \mathrm{~mL} / \mathrm{min}$, where $\mathrm{A}$ is $0.1 \mathrm{M}$ triethylammonium bicarbonate (TEAB) buffer, $\mathrm{pH} 7$, and $\mathrm{B}$ is acetonitrile (ACN).

After the purification of our product, the deprotection from the trityl group was performed. To this purpose, the lyophilized oligomer was dissolved in $0.1 \mathrm{M}$ triethylammonium acetate (TEAA) buffer, to have a final concentration of $7 \times 10^{-4} \mathrm{M}$, and treated with 0.15 volumes of the final volume of $1 \mathrm{M}$ aqueous silver nitrate solution. After $30 \mathrm{~min}$ of thoroughly mixing, 0.2 volumes of $1 \mathrm{M}$ DTT solution were added. The solution was stirred for $5 \mathrm{~min}$ and then centrifuged to remove the silver DTT complex. The supernatant was collected and the precipitate was washed with TEAA $0.1 \mathrm{M}$ and centrifuged for the second time. The combined supernatants were purified by Sep-Pak cartridges (C-18) to remove the excess of DTT. The obtained fractions were collected and dried under vacuum. Samples concentrations were determined in water by measuring the absorbance at $260 \mathrm{~nm}$ at $90^{\circ} \mathrm{C}$ using the nearest-neighbor calculated molar extinction coefficient of d [5 $5^{\prime}$ GGTTGGTGTGGTTGG3 $\left.{ }^{\prime}\right] \varepsilon=$ $143,000 \mathrm{M}^{-1} \mathrm{~cm}^{-1}$.

Finally, the sample was dissolved in PBS buffer (SigmaAldrich; $10 \mathrm{mM}$ phosphate buffer, $2.7 \mathrm{mM} \mathrm{KCl}, 137 \mathrm{mM} \mathrm{NaCl}$, $\mathrm{pH}$ 7.4), and the corresponding quadruplex was formed by heating the sample at $90^{\circ} \mathrm{C}$ and slowly cooling at room temperature.

2.2. Thiolated-TBA Self-Assembling. Self-assembling TBA-SH (4904.72 Da) on gold-coated quartz resonator was performed flowing $1 \mu \mathrm{M}$ TBA-SH solution in phosphate buffer $20 \mathrm{mM}$ $\mathrm{pH} 7.4$ for $100 \mathrm{~min}$ at room temperature. Three flowing cycles were performed in order to refresh the solution in contact with gold quartz surface.

\subsection{Quartz Crystal Microbalance and Thrombin Monitoring.}

The mass variations were measured by a QCM instrument (Novaetech S.r.l., Italy), connected to a computer by a producer-released software. The quartz resonators (QRs) (IEV S.r.l., Italy) are characterized by a fundamental nominal frequency of $10 \mathrm{MHz}$, a blank diameter of $8 \mathrm{~mm}$, and a gold lamina diameter of $4.5 \mathrm{~mm}$. The theoretical (in vacuum) declared sensitivity is of the order of $1 \mathrm{ng} /\left(\mathrm{cm}^{2} \mathrm{~Hz}\right)$. The fluidic apparatus consists of a GILSON peristaltic pump, two Tygon silicone tubes with diameters of $0.76 \mathrm{~mm}$ for the in and out flows, and a $30 \mu \mathrm{L}$ cell containing the QR.

After TBA-SH self-assembling, the interaction monitoring of human $\alpha$-thrombin (TB) (36700 Da) purchased from Haematologic Technologies Inc. was performed as described below. TB aliquots were solubilized in phosphate buffer $20 \mathrm{mM}$ pH 7.4 in order to obtain 20,50, and $100 \mathrm{nM}$ solution concentrations. Each solution was injected into QCM flow chamber. A control experiment was performed monitoring the interaction between TBA and $5 \mu \mathrm{M}$ Human Serum Albumin (HSA) purchased from Sigma-Aldrich.

2.4. Circular Dichroism. Circular Dichroism (CD) spectra were recorded at $25^{\circ} \mathrm{C}$ on a Jasco J-715 spectropolarimeter equipped with a Jasco JPT423S Peltier, using a $0.1 \mathrm{~cm}$ path length quartz cuvette, with a reaction volume of $500 \mu \mathrm{L}$. The TBA-SH sample was prepared at $20 \mu \mathrm{M}$ concentration in PBS buffer. The spectra were averaged over three scans. The buffer baseline was subtracted from each spectrum and the spectra were normalized to have zero at $320 \mathrm{~nm}$. CD melting curve was registered as a function of temperature (range $20-90^{\circ} \mathrm{C}$ ) for the quadruplex at its maximum Cotton effect wavelength.

2.5. Atomic Force Microscopy. $20 \mu \mathrm{L}$ of TBA $(2.7 \mathrm{mM}$ in deionized water) and TB $(2 \mu \mathrm{M}$ in deionized water $)$ was deposited on two pieces of crystalline silicon (Virginia 


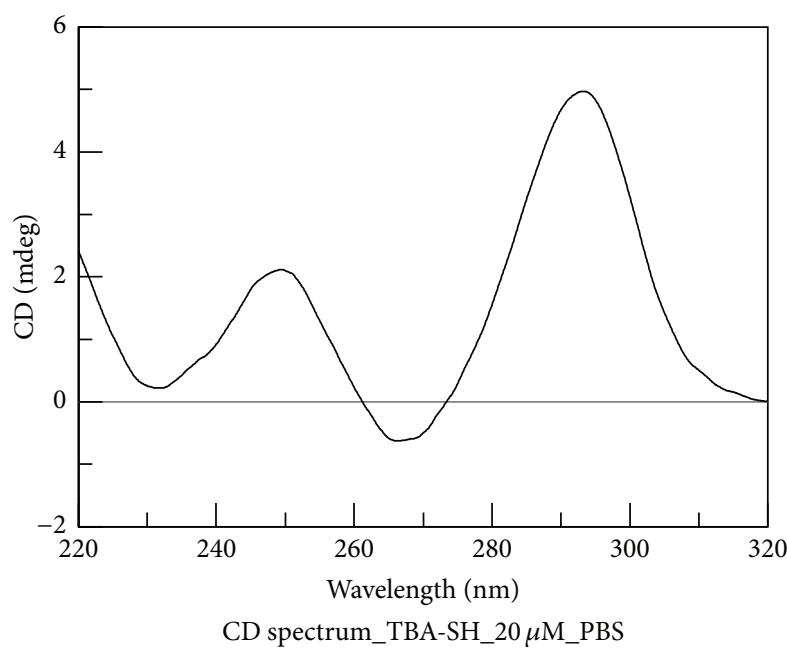

(a)

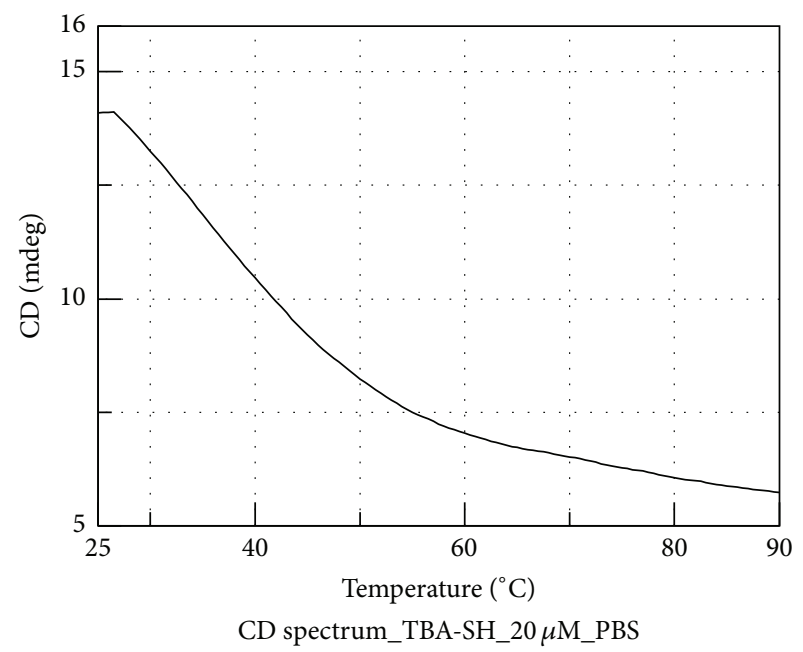

(b)

FIGURE 1: CD spectrum (a) and CD melting profile (b) of TBA-SH in PBS buffer.

Semiconductors, Inc.; $\mathrm{p}+$ doped, $\langle 100\rangle$ oriented, and $400 \mu \mathrm{m}$ thick, with $0.003 \Omega \mathrm{cm}$ resistivity) and dried at room temperature. Samples were washed with deionized water and dried in a stream of nitrogen gas. Morphology of biomolecules deposited on silicon was investigated by Atomic Force Microscopy (AFM) using a XE-100 microscope from Park Systems. Surface imaging was obtained in noncontact mode using silicon/aluminium coated cantilevers (PPP-NCHR $10 \mathrm{M}$, Park Systems) $125 \mathrm{~mm}$ long with a resonance frequency between 200 and $400 \mathrm{kHz}$ and a nominal force constant of $42 \mathrm{~N} / \mathrm{m}$. The scan frequency was typically $1 \mathrm{~Hz}$ per line. The scan area in surface analysis was $2 \mu \mathrm{m} \times 2 \mu \mathrm{m}$.

2.6. Spectroscopic Ellipsometry. Spectroscopic ellipsometry (SE) measurements were performed by a Jobin Yvon UVISELNIR phase modulated spectroscopic ellipsometer apparatus, at an incidence angle of $65^{\circ}$ over the range $500-1600 \mathrm{~nm}$ with a resolution of $5 \mathrm{~nm}$. The instrument measures the spectral variation of parameters $I_{s}$ and $I_{c}$ related to the ellipsometric angles $\Psi$ and $\Delta$ through the relation:

$$
\begin{aligned}
& I_{s}=\sin 2 \Psi \sin \Delta \\
& I_{c}=\sin 2 \Psi \cos \Delta,
\end{aligned}
$$

where $\Psi$ and $\Delta$ are defined from the fundamental equation of ellipsometry:

$$
\frac{r_{p}}{r_{s}}=\tan \Psi e^{i \Delta}
$$

with $r_{p}$ and $r_{s}$ being the complex reflection coefficients of the light polarized parallel and perpendicular to the incidence plane. Refractive indexes of TBA and TB and the thicknesses of biomaterials self-assembled on gold substrate were determined from the ellipsometric data analysis using Delta Psi software [27].

\section{Results and Discussion}

The synthetized sequence TBA-SH, namely, HS- $\left(\mathrm{CH}_{2}\right)_{6}$ $5^{\prime}$ GGTTGGTGTGGTTGG-3' ${ }^{\prime}$, was characterized by Circular Dichroism (CD) and CD melting in order to attest its ability to fold into monomolecular antiparallel chair-like Gquadruplex structure, adopted by the unmodified TBA in $\mathrm{Na}^{+}$- and $\mathrm{K}^{+}$-containing aqueous buffer. The results showed that TBA-SH folded into G-quadruplex structure in PBS buffer (the same used for all experiments on QCM sensor) despite the presence of thiol-modified alkyl chain at its $5^{\prime}$ terminus. The $\mathrm{CD}$ spectrum showed a positive maximum at $294 \mathrm{~nm}$ and a negative minimum at around $260 \mathrm{~nm}$, which are indicative for a TBA-like antiparallel quadruplex arrangement $[15,28]$. Moreover, the CD melting curve of TBA-SH recorded at $260 \mathrm{~nm}$ disclosed $T_{m}$ of $33^{\circ} \mathrm{C}$ for the quadruplex to random coil transition, very close to $T_{m}$ of the pure TBA in the same buffer (Figure 1) [16, 29].

A preliminary characterization of TBA and TB molecule structures was performed by AFM measurements. To this aim, TBA and TB were independently adsorbed on flat silicon supports (average roughness $<2 \mathrm{~nm}$ ), as described in Section 2.5, and studied separately. The results of morphologic characterization at nanoscopic level are shown in Figure 2. In case of TBA (Figure 2(a)), large and irregular aggregates constituted by small features of few nanometers (5-10) could be detected. The biofilm thickness ranged between 20 and $140 \mathrm{~nm}$. Quite differently, TB (Figure 2(b)) aggregated in a biolayer of average width of about $10 \mathrm{~nm}$, but exposing some much larger structures, up to $800 \mathrm{~nm}$, and with height included between 60 and $160 \mathrm{~nm}$.

Real-time monitoring of TBA-SH self-assembling on gold and its interaction with TB was then quantified by QCM measurements, which is a well-established technique in quantification of TBA-TB interaction [30, 31]. In Figure 3, the oscillation frequency $f$ of the quartz resonator (QR) used in our experiments is reported as function of time. The starting 


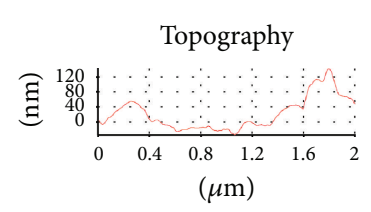

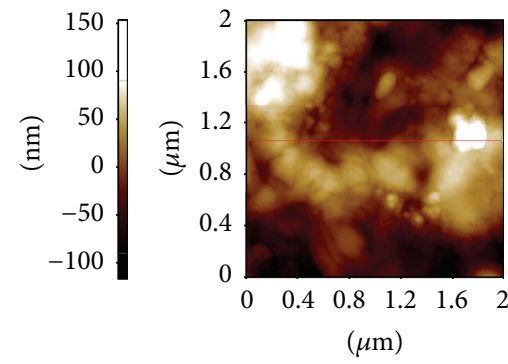
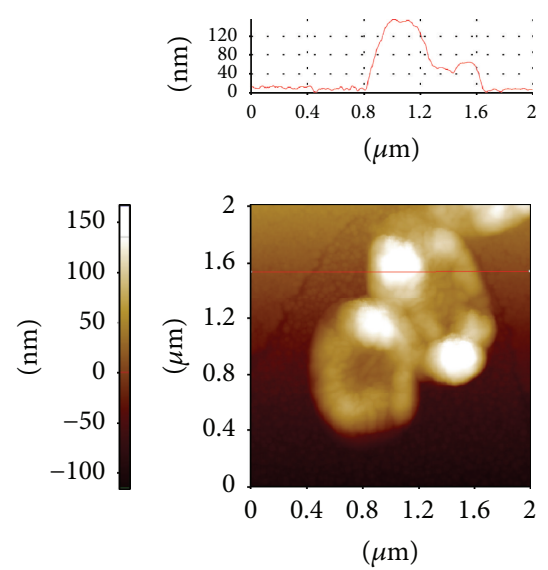

Phase
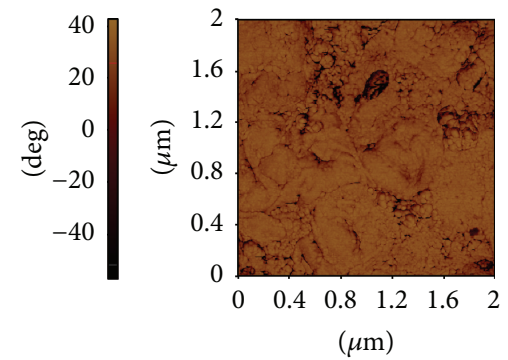

(a)
3D

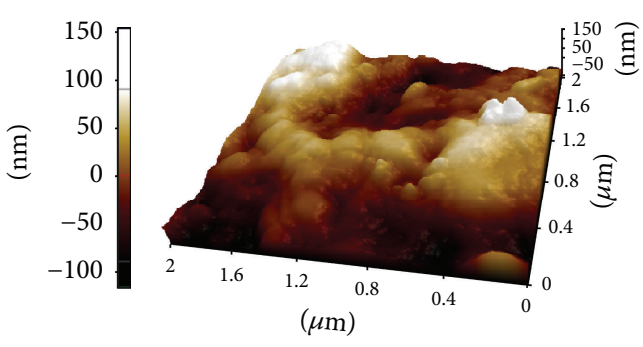

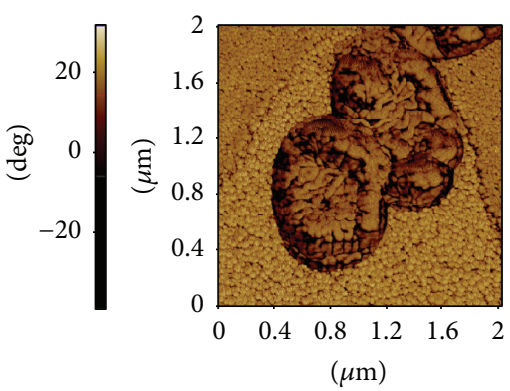

(b)

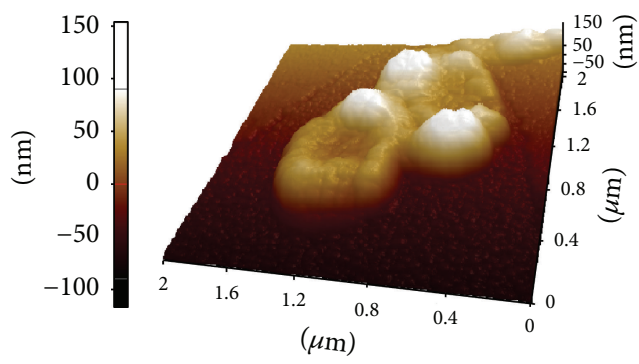

FIGURE 2: AFM topography images and cross profile (first column) of TBA (a) and TB (b) deposited on silicon surfaces. Corresponding phase (second column) and 3D (third column) images.

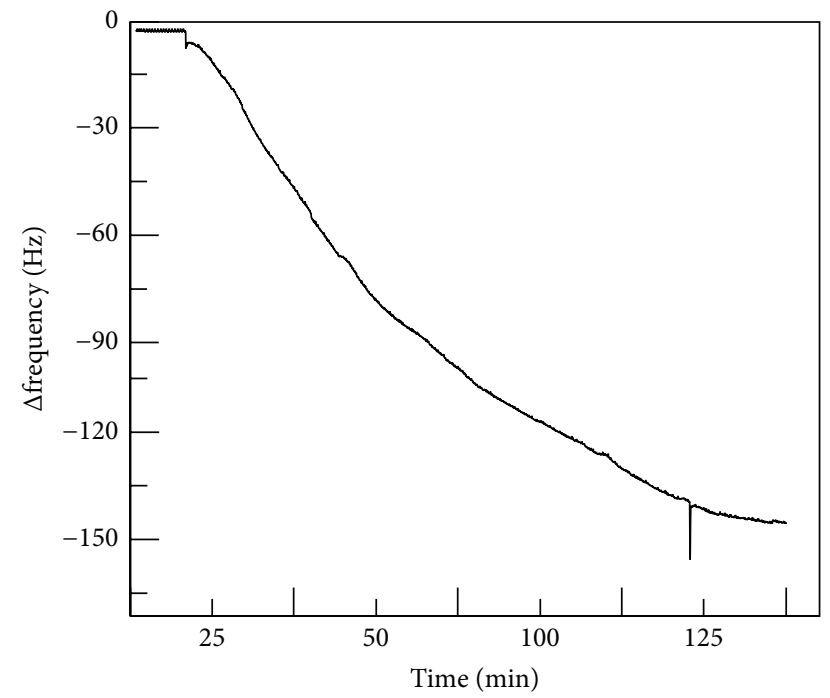

FIGURE 3: Real-time monitoring of TBA-SH self-assembling onto QR surfaces.

frequency, stabilized in phosphate buffer solutions, resulted in an absolute variation $\Delta f$ of $160 \pm 10 \mathrm{~Hz}$. According to Sauebrey's equation and QCM/QR geometric features, reported in Section 2.3, the measured $\Delta f$ corresponded to $0.112 \pm 0.007 \mu \mathrm{g}$ of TBA-SH adsorbed onto QR. Three flowing cycles of TBA-SH solution were performed during selfassembling study, in order to refresh the solution in contact with QR: it can be noted that a stable self-assembling of TBA$\mathrm{SH}$ on gold was achieved already after the first flowing cycle.

Extensive rinsing washes were performed to remove TBA-SH molecules not strongly bound to QR surface, and then real-time interaction monitoring with TB molecules was studied.

Figure 4 reports the frequency change $\Delta f$ due to three binding cycles of TB solutions at increasing concentrations, compared to a control experiment performed by flowing Human Serum Albumin at $5 \mu \mathrm{M}$ concentration. TB interaction caused $\Delta f$ of 17,5 , and $9 \mathrm{~Hz}$ after injection of TB solutions with concentrations of 20,50, and $100 \mathrm{nM}$, respectively. Each TB $\Delta f$ corresponded to $11.9,3.5$, and $6.3 \mathrm{ng}$ of TB adsorbed onto QR (Table 1), reaching a final TB adsorbed mass of $22 \mathrm{ng}$.

In order to exclude aspecific binding of $\mathrm{TB}$ on a bare gold quartz surface, $100 \mathrm{nM}$ solution of TB was flowed in the microfluidic circuit right through the QR surface. Experimental data (see Figure S1 in Supplementary Material 
TABLE 1: Comparison between TB mass injected and adsorbed onto QR surface.

\begin{tabular}{lccc}
\hline & TB (1st cycle) & TB (2nd cycle) & TB (3rd cycle) \\
\hline Mass injected & $22 \mathrm{ng}$ & $50 \mathrm{ng}$ & $110 \mathrm{ng}$ \\
$\Delta f$ & $17 \mathrm{~Hz}$ & $5 \mathrm{~Hz}$ & $9 \mathrm{~Hz}$ \\
Mass adsorbed & $11.9 \mathrm{ng}$ & $3.5 \mathrm{ng}$ & $6.3 \mathrm{ng}$ \\
\hline
\end{tabular}

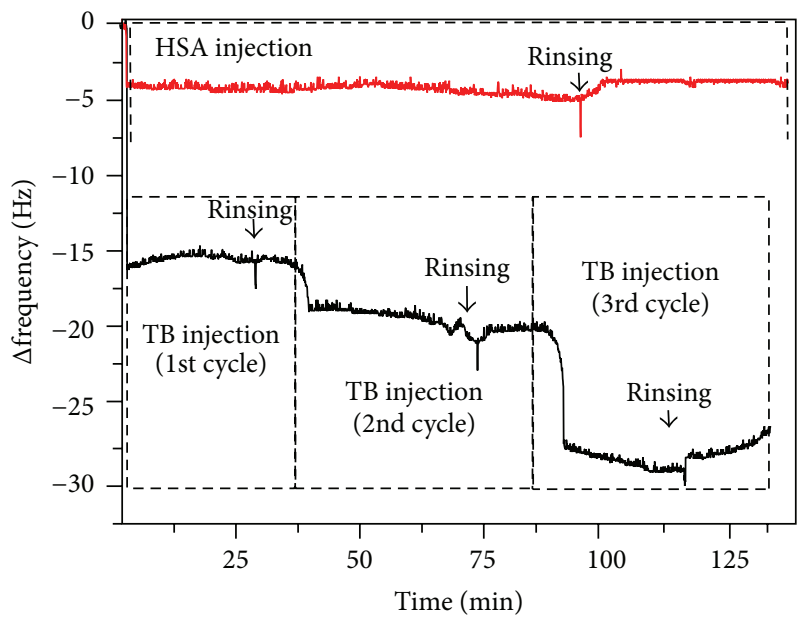

FIGURE 4: Real-time monitoring of different concentrations (20, 50 , and $100 \mathrm{nM}$ ) of TB by a TBA modified gold substrate (black line). Real-time monitoring of $5 \mu \mathrm{M}$ HSA by a TBA modified gold substrate (red line) as control.

available online at http://dx.doi.org/10.1155/2016/3561863) highlighted that TB injection produced $\Delta f$ of only $3 \mathrm{~Hz}$, which means that really few TB molecules stopped on QR surface, probably due to weak electrostatic aspecific interactions.

TBA-TB strong binding was proved by stability of QR frequency values even after extensive rinsing steps succeeding TB injection, but this biomolecular interaction did not led to an irreversible complex: it is well known that TBA denatures at high temperature, thus releasing $\mathrm{TB}$ molecules $[32,33]$. After TB binding experiment, the $\mathrm{QR}$ surface was rinsed at $55^{\circ} \mathrm{C}$ for $1 \mathrm{~h}$ and then used again in QCM set up in order to prove complete reversibility of QR signal (data reported in Supplementary Materials): on exposure to $20 \mathrm{nM}$ and $50 \mathrm{nM}$ injection of TB, $\Delta f$ change of about $20 \mathrm{~Hz}$ resulted, confirming reversibility of the biosystem.

The plot of $\Delta f$ as a function of TB concentration could be fitted by OriginLab Software ${ }^{\mathrm{TM}}$ (see Figure 5) Hill equation [34]:

$$
y=\Delta f_{\max } \frac{[\mathrm{TB}]^{\alpha}}{K_{d}^{\alpha}+[\mathrm{TB}]^{\alpha}},
$$

where $\Delta f_{\max }$ is the saturation point; $K_{d}$ is the affinity constant; [TB] is TB concentration; $\alpha$ is Hill coefficient $[35,36]$. From the fit, we get an Hill coefficient equal to 1, which means that just one site of reaction was present, and the affinity of

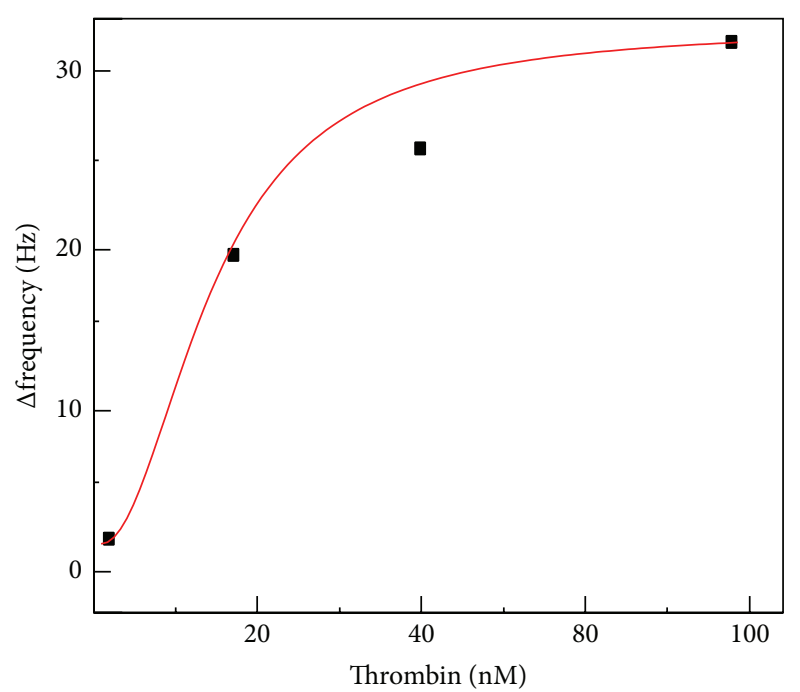

FIGURE 5: Quartz frequency variation versus TB concentration. Experimental data (black symbols) were fitted using Hill kinetic model.

the biomolecule for its ligand was not dependent on whether or not other ligand molecules were already bound; therefore, the Hill equation was formally equivalent to a Langmuir equation [37]. Furthermore, we estimated a system affinity constant of $17.7 \pm 0.3 \mathrm{nM}$, a sensitivity of $0.42 \pm 0.03 \mathrm{~Hz} \mathrm{nM}^{-1}$ (calculated in the range of linearity of system response), and a limit of detection (LOD) of $240 \pm 20 \mathrm{pM} . K_{d}$ was found comparable to previous studies [38-42]. LOD value was found lower than other well-known very sensitive assays [43-45], but higher than QCM modified one [46].

A parallel investigation of TBA-TB binding on gold surface was performed by using an all-optical, label-free characterization technique: the spectroscopic ellipsometry, generally useful for refractive indexes and biofilm thicknesses estimation [47-49]. The experimental data were fitted using the fixed index model for transparent media (data not shown here). Refractive indexes of 1.674 and 1.558 were obtained for TBA and for TB, respectively. Figure 6 shows $I_{s}$ and $I_{c}$ experimental spectra in the case of thiolated-TBA selfassembled on gold substrate before and after the interaction with $110 \mathrm{nM}$ thrombin, together with calculated spectra and material models used to fit them. TBA and TB were modeled by a simple homogeneous layer using the previously calculated refractive index. The fitting parameters are the film thicknesses. A TBA thickness of $4(1) \mathrm{nm}\left(\chi^{2}=3\right)$ was estimated analyzing the sample before the interaction with TB. After TB recognition, ellipsometry reveals that the presence of a second film of $13(1) \mathrm{nm}\left(\chi^{2}=5\right)$ was observed due to the presence of thrombin bound to TBA molecules. The results of this analysis were the average of three different measurements on the same sample, in order to take into account film inhomogeneities. A negative control performed on another sample of TBA assembled on gold-coated quartz after exposure to $5 \mu \mathrm{M}$ HSA did not show any variation in biofilm thickness, demonstrating high selectivity of TBA-TB interaction. 
TABLE 2: Surface concentration value of TBA.

\begin{tabular}{lccccc}
\hline Molecule & $n_{f}$ & $d(\mathrm{~cm})$ & $M(\mathrm{~g} / \mathrm{mol})$ & $A\left(\mathrm{~cm}^{3} / \mathrm{mol}\right)$ & $\Gamma\left(\mu \mathrm{g} / \mathrm{cm}^{2}\right)$ \\
\hline TBA-SH & 1.674 & $(4 \pm 1) \times 10^{-7}$ & 4904.72 & 1022 & $0.07 \pm 0.02$ \\
\hline
\end{tabular}

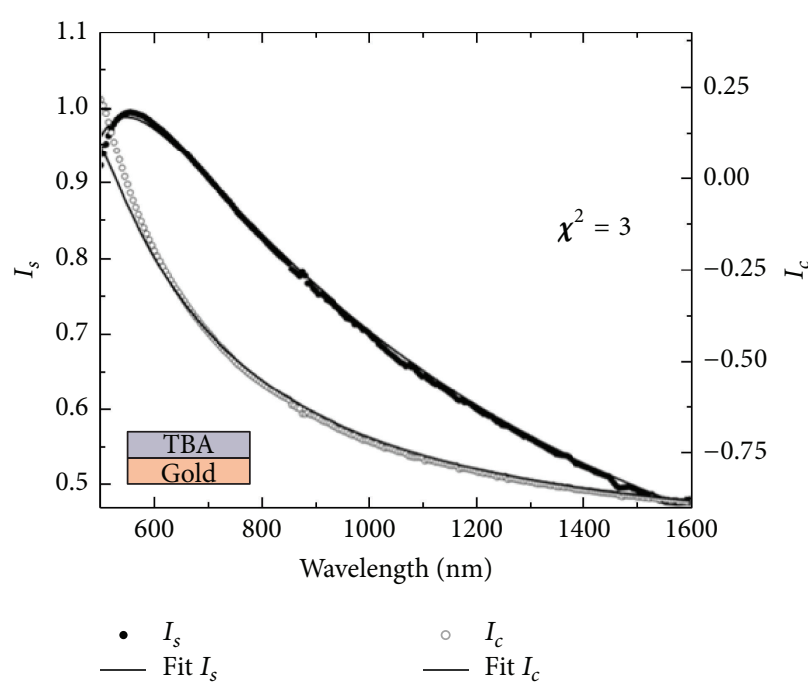

(a)

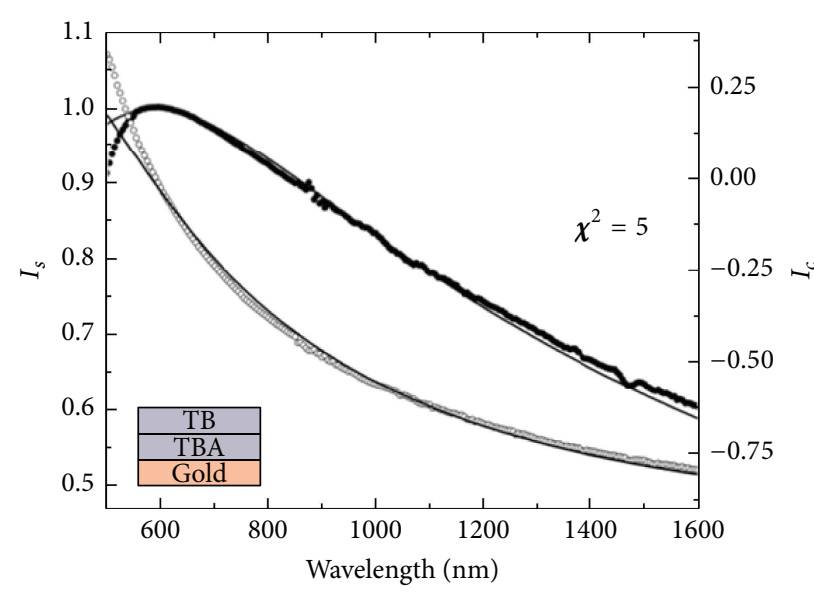

$\begin{array}{ll}- & I_{s} \\ - & \text { Fit } I_{s}\end{array}$

(b)

FIGURE 6: Measured and calculated $I_{s}$ and $I_{c}$ spectra of thiolated-TBA self-assembled on a gold substrate before (a) and after (b) interaction with TB.

The surface concentration $\Gamma\left(\mu \mathrm{g} / \mathrm{cm}^{2}\right)$ of TBA biofilm self-assembled on gold substrate can be also calculated from ellipsometric data by using the Cuypers formula [50]:

$$
\Gamma=0.1 d \frac{M}{A} \frac{\left(n_{f}^{2}-1\right)}{\left(n_{f}^{2}+2\right)}
$$

where $A$ is the molar refractivity $\left(\mathrm{cm}^{3} / \mathrm{mol}\right), M$ is the molecular weight, and $d$ and $n_{f}$ are the thickness and the refractive index of the biofilm (determined by SE).

In Table 2, we reported the parameters used to calculate $\Gamma$ and the value of $\Gamma$, revealing a good surface coverage comparable to previous study [51]. The molar refractivity of TBA was obtained by adding the known values of its constituent atoms [50].

\section{Conclusions}

In this work, quartz crystal microbalance and spectroscopic ellipsometry are used to characterize the recognition of thrombin by thiolated-thrombin binding aptamer selfassembled on gold substrate. A selective and specifc biomolecular interaction, characterized by low detection limit $(240$ $\pm 20 \mathrm{pM})$ and good sensitivity $\left(0.42 \pm 0.03 \mathrm{~Hz} \mathrm{nM}^{-1}\right)$, is demonstrated. The work provides a good starting point for the development of a nanostructured biosensor in order to realize a future Lab-on-Chip (LoC) device for vascular diseases early diagnosis.

\section{Competing Interests}

The authors declare that they have no competing interests.

\section{References}

[1] H. Jerius, A. Beal, D. Woodrum, A. Epstein, and C. Brophy, "Thrombin-induced vasospasm: cellular signaling mechanisms," Surgery, vol. 123, no. 1, pp. 46-50, 1998.

[2] N. Vergnolle, M. D. Hollenberg, and J. L. Wallace, "Proand anti-inflammatory actions of thrombin: a distinct role for proteinase-activated receptor-1 $\left(\mathrm{PAR}_{1}\right)$," British Journal of Pharmacology, vol. 126, no. 5, pp. 1262-1268, 1999.

[3] J. Zain, Y.-Q. Huang, X. Feng, M. L. Nierodzik, J.-J. Li, and S. Karpatkin, "Concentration-dependent dual effect of thrombin on impaired growth/apoptosis or mitogenesis in tumor cells," Blood, vol. 95, no. 10, pp. 3133-3138, 2000.

[4] D. M. Tasset, M. F. Kubik, and W. Steiner, "Oligonucleotide inhibitors of human thrombin that bind distinct epitopes," Journal of Molecular Biology, vol. 272, no. 5, pp. 688-698, 1997.

[5] M. Tsiang, A. K. Jain, K. E. Dunn, M. E. Rojas, L. L. K. Leung, and C. S. Gibbs, "Functional mapping of the surface residues of human thrombin," The Journal of Biological Chemistry, vol. 270, no. 28, pp. 16854-16863, 1995.

[6] U. Abildgaard, "Inhibition of the thrombin-fibrinogen reaction by heparin in the absence of cofactor," Scandinavian Journal of Haematology, vol. 5, no. 6, pp. 432-439, 1968.

[7] H. Yang, J. Ji, Y. Liu, J. Kong, and B. Liu, "An aptamer-based biosensor for sensitive thrombin detection," Electrochemistry Communications, vol. 11, no. 1, pp. 38-40, 2009. 
[8] A. D. Ellington and J. W. Szostak, "In vitro selection of RNA molecules that bind specific ligands," Nature, vol. 346 , no. 6287, pp. 818-822, 1990.

[9] T.-C. Chiu and C.-C. Huang, "Aptamer-functionalized nanobiosensors," Sensors, vol. 9, no. 12, pp. 10356-10388, 2009.

[10] R. D. Jenison, S. C. Gill, A. Pardi, and B. Polisky, "Highresolution molecular discrimination by RNA," Science, vol. 263, no. 5152, pp. 1425-1429, 1994.

[11] A. A. Haller and P. Sarnow, "In vitro selection of a 7-methylguanosine binding RNA that inhibits translation of capped mRNA molecules," Proceedings of the National Academy of Sciences of the United States of America, vol. 94, no. 16, pp. 85218526, 1997.

[12] M. Sassanfar and J. W. Szostak, "An RNA motif that binds ATP," Nature, vol. 364, no. 6437, pp. 550-553, 1993.

[13] C. Mannironi, A. Di Nardo, P. Fruscoloni, and G. P. TocchiniValentini, "In vitro selection of dopamine RNA ligands," Biochemistry, vol. 36, no. 32, pp. 9726-9734, 1997.

[14] A. Geiger, P. Burgstaller, H. Von der Eltz, A. Roeder, and M. Famulok, "RNA aptamers that bind L-arginine with submicromolar dissociation constants and high enantioselectivity," Nucleic Acids Research, vol. 24, no. 6, pp. 1029-1036, 1996.

[15] T. Mairal, V. C. Özalp, P. Lozano Sánchez, M. Mir, I. Katakis, and C. K. O'Sullivan, "Aptamers: molecular tools for analytical applications," Analytical and Bioanalytical Chemistry, vol. 390, no. 4, pp. 989-1007, 2008.

[16] S. Song, L. Wang, J. Li, C. Fan, and J. Zhao, "Aptamer-based biosensors," TrAC-Trends in Analytical Chemistry, vol. 27, no. 2, pp. 108-117, 2008.

[17] C. Sun, Q. Han, D. Wang et al., "A label-free and high sensitive aptamer biosensor based on hyperbranched polyester microspheres for thrombin detection," Analytica Chimica Acta, vol. 850, pp. 33-40, 2014.

[18] T. Coppola, M. Varra, G. Oliviero et al., "Synthesis, structural studies and biological properties of new TBA analogues containing an acyclic nucleotide," Bioorganic and Medicinal Chemistry, vol. 16, no. 17, pp. 8244-8253, 2008.

[19] N. Borbone, M. Bucci, G. Oliviero et al., "Investigating the role of T7 and T12 residues on the biological properties of thrombinbinding aptamer: Enhancement of anticoagulant activity by a single nucleobase modification," Journal of Medicinal Chemistry, vol. 55, no. 23, pp. 10716-10728, 2012.

[20] T. Hianik, V. Ostatná, M. Sonlajtnerova, and I. Grman, "Influence of ionic strength, $\mathrm{pH}$ and aptamer configuration for binding affinity to thrombin," Bioelectrochemistry, vol. 70, no. 1, pp. 127-133, 2007.

[21] S. Balamurugan, A. Obubuafo, S. A. Soper, R. L. McCarley, and D. A. Spivak, "Designing highly specific biosensing surfaces using aptamer monolayers on gold," Langmuir, vol. 22, no. 14, pp. 6446-6453, 2006.

[22] M. C. Dixon, "Quartz crystal microbalance with dissipation monitoring: enabling real-time characterization of biological materials and their interactions," Journal of Biomolecular Techniques, vol. 19, no. 3, pp. 151-158, 2008.

[23] D. R. P. Morris, J. Fatisson, A. L. J. Olsson, N. Tufenkji, and A. R. Ferro, "Real-time monitoring of airborne cat allergen using a QCM-based immunosensor," Sensors and Actuators B: Chemical, vol. 190, pp. 851-857, 2014.

[24] J. Politi, A. Caliò, P. Dardano, M. Iodice, I. Rea, and L. De Stefano, "Bioconjugation of heavy metal-binding proteins on surface: an optical and gravimetric characterization," Procedia Engineering, vol. 87, pp. 292-295, 2014.
[25] R. Spera, T. T. B. Correia, and C. Nicolini, "NAPPA based nanogravimetric biosensor: preliminary characterization," Sensors and Actuators B: Chemical, vol. 182, pp. 682-688, 2013.

[26] D. Musumeci, G. Oliviero, G. N. Roviello, E. M. Bucci, and G. Piccialli, "G-quadruplex-forming oligonucleotide conjugated to magnetic nanoparticles: synthesis, characterization, and enzymatic stability assays," Bioconjugate Chemistry, vol. 23, no. 3, pp. 382-391, 2012.

[27] HoribaJobinYvon DELTA PSI Software manual, ver. 2.4.3 158. (Horiba Scientific, 2011).

[28] S. Nagatoishi, Y. Tanaka, and K. Tsumoto, "Circular dichroism spectra demonstrate formation of the thrombin-binding DNA aptamer G-quadruplex under stabilizing-cation-deficient conditions," Biochemical and Biophysical Research Communications, vol. 352, no. 3, pp. 812-817, 2007.

[29] M. Scuotto, E. Rivieccio, A. Varone et al., "Site specific replacements of a single loop nucleoside with a dibenzyl linker may switch the activity of TBA from anticoagulant to antiproliferative," Nucleic Acids Research, vol. 43, no. 16, pp. 7702-7716, 2015.

[30] P. He, L. Liu, W. Qiao, and S. Zhang, "Ultrasensitive detection of thrombin using surface plasmon resonance and quartz crystal microbalance sensors by aptamer-based rolling circle amplification and nanoparticle signal enhancement," Chemical Communications, vol. 50, no. 12, pp. 1481-1484, 2014.

[31] W. Tang, D. Wang, Y. Xu, N. Li, and F. Liu, "A self-assembled DNA nanostructure-amplified quartz crystal microbalance with dissipation biosensing platform for nucleic acids," Chemical Communications, vol. 48, no. 53, pp. 6678-6680, 2012.

[32] B. Pagano, L. Martino, A. Randazzo, and C. Giancola, "Stability and binding properties of a modified thrombin binding aptamer," Biophysical Journal, vol. 94, no. 2, pp. 562-569, 2008.

[33] G. W. Lehman and J. P. McTague, "Melting of DNA," The Journal of Chemical Physics, vol. 49, pp. 3170-3179, 1968.

[34] A. V. Hill, "The possible effects of the aggregation of the molecules of h $\mu$ moglobin on its dissociation curves," Journal of Physiology, vol. 40, pp. 40-46, 1910.

[35] J. Politi, J. Spadavecchia, M. Iodice, and L. De Stefano, "Oligopeptide-heavy metal interaction monitoring by hybrid gold nanoparticle based assay," Analyst, vol. 140, no. 1, pp. 149155, 2015.

[36] J. Politi, J. Spadavecchia, G. Fiorentino, I. Antonucci, S. Casale, and L. De Stefano, "Interaction of Thermus thermophilus ArsC enzyme and gold nanoparticles naked-eye assays speciation between As(III) and As(V)," Nanotechnology, vol. 26, no. 43, Article ID 435703, 2015.

[37] S. Goutelle, M. Maurin, F. Rougier et al., "The Hill equation: a review of its capabilities in pharmacological modelling," Fundamental \& Clinical Pharmacology, vol. 22, no. 6, pp. 633$648,2008$.

[38] J. E. L. E. A. Sánchez, E. Baldrich, A. E. E. G. Radi et al., "Electronic 'off-on' molecular switch for rapid detection of thrombin," Electroanalysis, vol. 18, no. 19-20, pp. 1957-1962, 2006.

[39] A. Poturnayová, M. Šnejdárková, and T. Hianik, “DNA aptamer configuration affects the sensitivity and binding kinetics of thrombin," Acta Chimica Slovenica, vol. 5, no. 1, pp. 53-58, 2012.

[40] T. Hianik, "Detection of protein-aptamer interactions by means of electrochemical indicators and transverse shear mode method," in Aptamers in Bioanalysis, M. Mascini, Ed., chapter 5, pp. 101-128, John Wiley \& Sons Inc, Hoboken, NJ, USA, 2009. 
[41] Y. Xiao, A. A. Lubin, A. J. Heeger, and K. W. Plaxco, "Labelfree electronic detection of thrombin in blood serum by using an aptamer-based sensor," Angewandte Chemie International Edition, vol. 44, no. 34, pp. 5456-5459, 2005.

[42] L. De Stefano, I. Rea, P. Giardina, A. Armenante, and I. Rendina, "Protein-modified porous silicon nanostructures," Advanced Materials, vol. 20, no. 8, pp. 1529-1533, 2008.

[43] Y. Xiao, B. D. Piorek, K. W. Plaxco, and A. J. Heegert, "A reagentless signal-on architecture for electronic, aptamer-based sensors via target-induced strand displacement," Journal of the American Chemical Society, vol. 127, no. 51, pp. 17990-17991, 2005.

[44] F. Le Floch, H. A. Ho, and M. Leclerc, "Label-free electrochemical detection of protein based on a ferrocene-bearing cationic polythiophene and aptamer," Analytical Chemistry, vol. 78, no. 13, pp. 4727-4731, 2006.

[45] H. Wei, B. Li, J. Li, E. Wang, and S. Dong, "Simple and sensitive aptamer-based colorimetric sensing of protein using unmodified gold nanoparticle probes," Chemical Communications, vol. 36, pp. 3735-3737, 2007.

[46] T. Hianik, V. Ostatná, Z. Zajacová, E. Stoikova, and G. Evtugyn, "Detection of aptamer-protein interactions using QCM and electrochemical indicator methods," Bioorganic \& Medicinal Chemistry Letters, vol. 15, no. 2, pp. 291-295, 2005.

[47] I. Rea, P. Giardina, S. Longobardi et al., "Hydrophobin Vmh2glucose complexes self-assemble in nanometric biofilms," Journal of the Royal Society Interface, vol. 9, no. 75, pp. 2450-2456, 2012.

[48] M. Terracciano, I. Rea, J. Politi, and L. De Stefano, "Optical characterization of aminosilane-modified silicon dioxide surface for biosensing," Journal of the European Optical Society, vol. 8, Article ID 13075, 2013.

[49] P. Brocos, Á. Piñeiro, R. Bravo, and A. Amigo, "Refractive indices, molar volumes and molar refractions of binary liquid mixtures: concepts and correlations," Physical Chemistry Chemical Physics, vol. 5, no. 3, pp. 550-557, 2003.

[50] P. A. Cuypers, J. W. Corsel, M. P. Janssen, J. M. Kop, W. T. Hermens, and H. C. Hemker, "The adsorption of prothrombin to phosphatidylserine multilayers quantitated by ellipsometry," The Journal of Biological Chemistry, vol. 258, no. 4, pp. 24262431, 1983.

[51] C. Polonschii, S. David, S. Tombelli, M. Mascini, and M. Gheorghiu, "A novel low-cost and easy to develop functionalization platform. Case study: aptamer-based detection of thrombin by surface plasmon resonance," Talanta, vol. 80 , no. 5, pp. 21572164, 2010. 


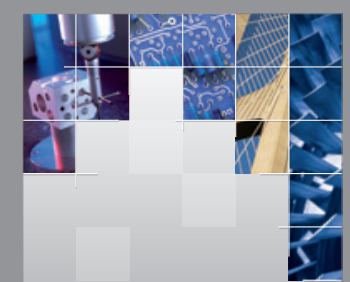

\section{Enfincering}
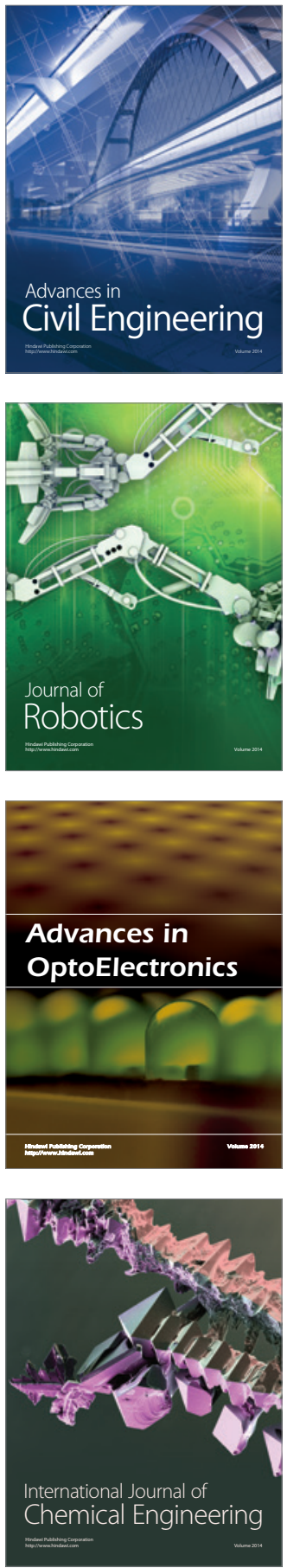

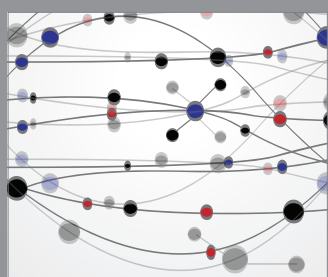

The Scientific World Journal

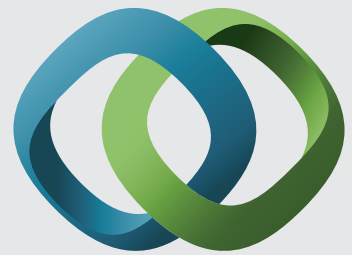

\section{Hindawi}

Submit your manuscripts at

http://www.hindawi.com
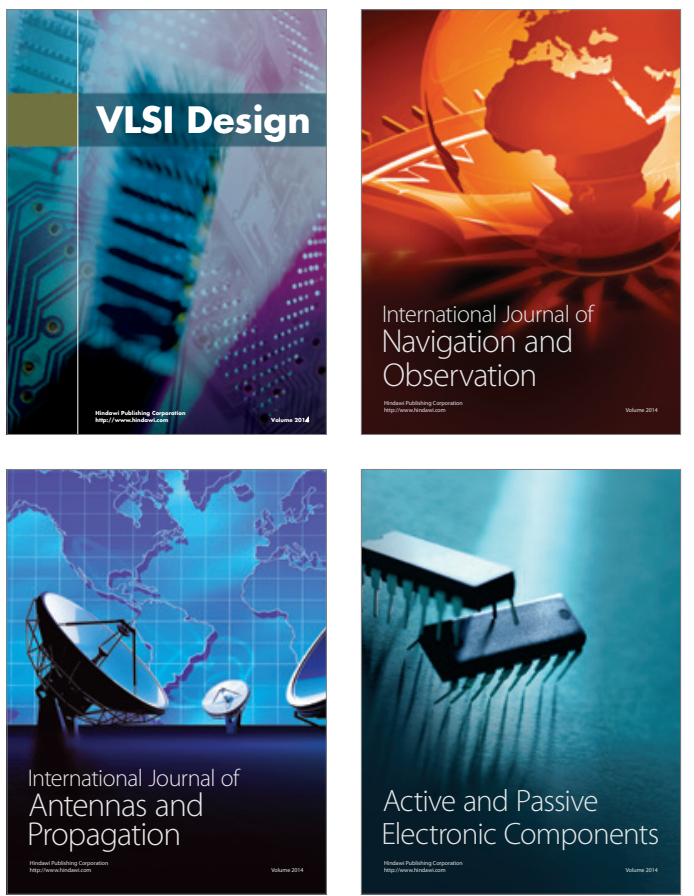
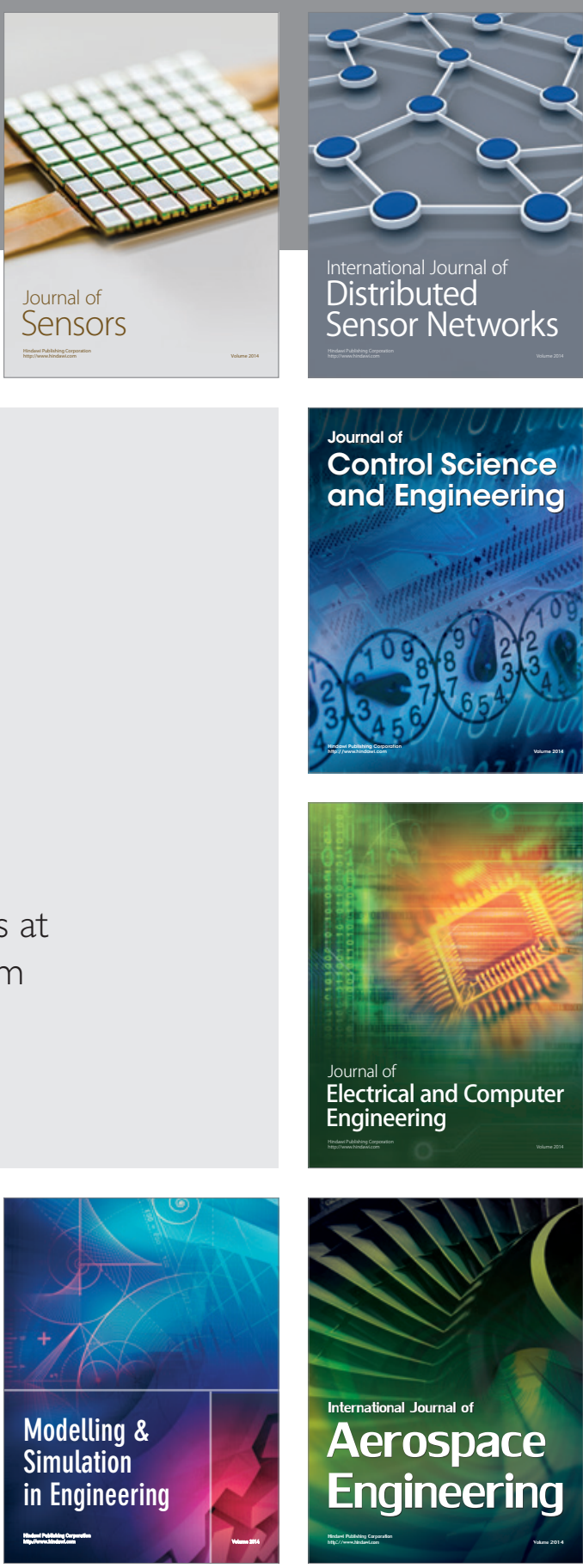

International Journal of

Distributed

Sensor Networks

Journal of

Control Science

and Engineering
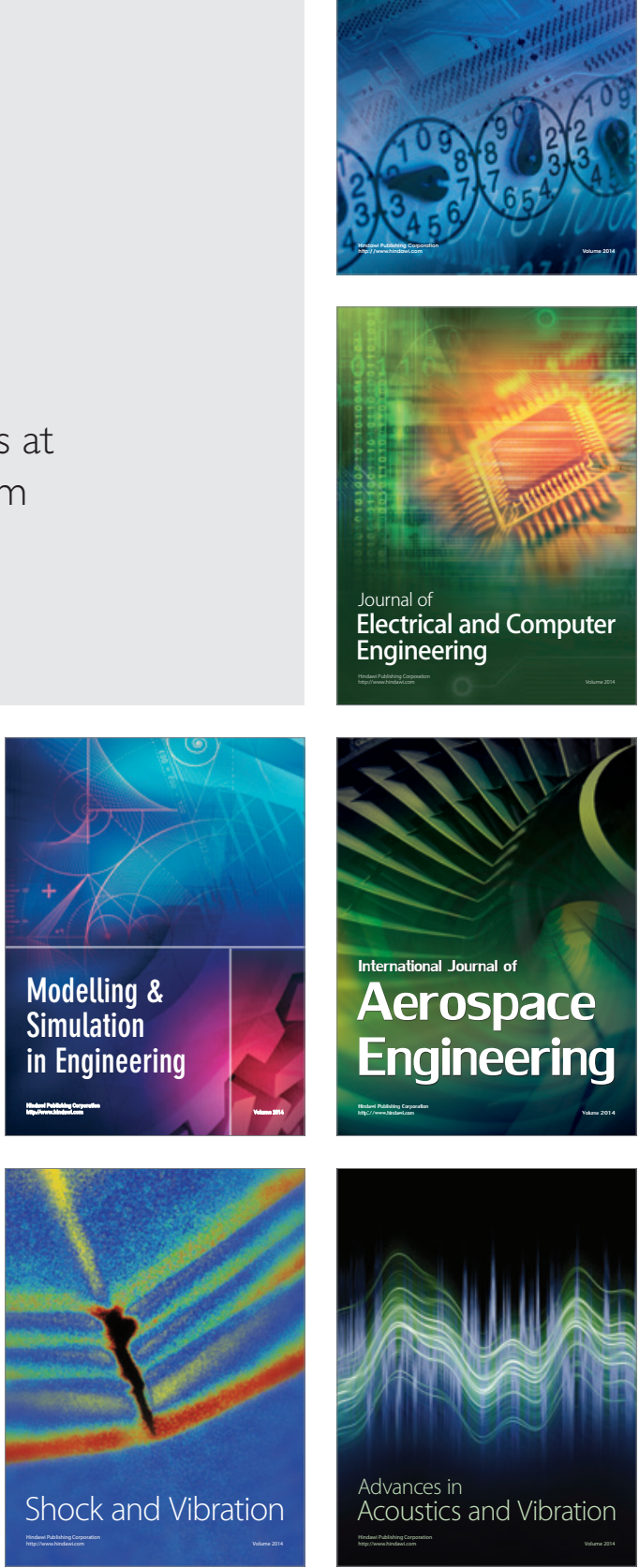